\title{
PLANOS DE CLASSIFICAÇÃO EM ARQUIVOS: ESTUDO COMPARATIVO DE PLANOS DE CLASSIFICAÇÃO NO CENÁRIO BRASILEIRO, ESPANHOL E PORTUGGUÊS
}

\author{
THIAGO ROBERTO LOPES * \\ URSULA BLATTMANN**
}

\begin{abstract}
RESUMO
O propósito desta pesquisa mostra um estudo comparativo de Planos de Classificação arquivística no cenário do Brasil, Portugal e Espanha. Trata-se de uma pesquisa documental, caracterizando-se como descritiva e bibliográfica. $O$ instrumento de coleta das informações foi um documento da Agência Nacional de Energia Elétrica, contendo o Plano de Classificação do órgão e, também, documentos da Administração Local de Portugal e O Cuadro de Clasificación de Fondos para a Administração Local da Espanha, além do Cuadro general de clasificación archivística. Por meio de estudos comparativos destes Planos de Classificação, da análise dos dados contidos nesses documentos e da revisão bibliográfica, foi possível apontar características em comum entre os Planos de Classificação em cada país, assim como as diferenças e os pontos positivos e negativos.
\end{abstract}

PALAVRAS-CHAVE: Arquivos - Classificação. Classificação arquivística. Planos de Classificação.

\begin{abstract}
ARCHIVES CLASSIFICATION PLANS: COMPARATIVE STUDY OF BRAZILIAN, SPAIN AND PORTUGAL CLASSIFICATION PLANS

This comparative study of Classification Plans in Brazilian, Spain and Portugal archives. This is a documentary research, being characterized as descriptive and bibliographical. The instrument for collecting information was an ANEEL document containing the Classification Plan of the body and also documents of the Local Administration of Portugal and the Table of Classification of Funds for Local Administration of Spain, in addition to the General Table of archival classification. Through comparative studies of these Classification Plans, analysis of the data contained in these documents and bibliographic review, it is possible to point out common characteristics between the Classification Plans in each country, as well as the differences and the positive and negative points.
\end{abstract}

KEYWORDS: Archival Classification. Archives - Classification. Classification Plans.

\footnotetext{
Acadêmico do Curso de Graduação em Arquivologia da Universidade Federal de Santa Catarina. E-mail: thiagoavai@hotmail.com.

Orientadora. Professora do Departamento de Ciência da Informação da Universidade Federal de Santa Catarina. Doutora em Engenharia de Produção. Atua no Programa de Pós-Graduação em Ciência da Informação. E-mail: ursula.blattmann@ufsc.br.
} 


\section{INTRODUÇÃO}

A Classificação em arquivos consiste em espelhar e oferecer ao usuário a visualização das funções e atividades exercidas pelo organismo produtor. Com esse conceito, pode-se entender a classificação de forma lógica e estruturada de forma a apresentar uma estrutura hierarquizada e de acordo com o que nos apresenta 0 arquivo em sua forma propriamente dita. (GONÇALVES, 1998)

A Classificação arquivística é primordial nos arquivos e, quando realizada de forma adequada, ajuda o usuário em seu dia a dia nas pesquisas realizadas em todas as áreas. De acordo com o Conselho Nacional de Arquivos e suas diretrizes, no que tange às atividades-meio da administração pública, a classificação é a norteadora e definidora da organização física e intelectual dos documentos arquivados, servindo como referencial teórico-básico para a sua recuperação.

p. 9):

Segundo o Conselho Nacional de Arquivos (CONARQ, 2001

A classificação por assuntos é utilizada com o objetivo de agrupar os documentos sob um mesmo tema, como forma de agilizar sua recuperação e facilitar as tarefas arquivísticas relacionadas com a avaliação, seleção, eliminação, transferência, recolhimento e acesso a esses documentos, uma vez que o trabalho arquivístico é realizado com base no conteúdo do documento, o qual reflete a atividade que o gerou e determina o uso da informação nele contida.

Deste modo, elaborados os Planos de Classificação e tabela de temporalidade e avaliação de documentos, necessita-se observar os procedimentos específicos para cada instituição. Dessa maneira, buscou-se esclarecer quais os tipos, características e procedimentos de Planos de Classificação arquivística podem ser utilizados, não somente em Universidades como em quaisquer Instituições, seja de caráter público e privado, expondo as características inerentes e suas facetas.

O estudo apresenta como objetivo geral: analisar, segundo a literatura, os conceitos e aplicações dos Planos de Classificação da Agencia Nacional de Energia Elétrica (ANEEL) e planos de classificação de Portugal e Espanha. Especificamente: a)Verificar quais os tipos de planos de classificação existentes; b) Descrever os procedimentos de classificação dos documentos utilizados nas instituições; c) Descrever a importância de classificar os documentos 
de arquivo.

\section{REFERENCIAL TEÓRICO}

O referencial teórico está estruturado com embasamento na classificação em arquivos, com as definições e as etapas. A seguir, apresentam-se os tipos, planos e procedimentos de classificação em arquivos.

\subsection{Tipos de classificação em arquivos}

De acordo com Gonçalves (1998. p. 23 e 24), não há um consenso em relação aos métodos de classificação funcional, organizacional e por assuntos. "[...] A elaboração do plano não pode estar desconectada da preocupação com sua aplicação." Além disso, a autora cita as três qualidades para que um plano de classificação possa permitir ser aplicado sem grandes dificuldades: "simplicidade, flexibilidade e expansibilidade".

Simplicidade: para que possa ser entendido pelo maior número de pessoas possível. Flexibilidade: que não seja engessado, isto é, torne-se acessível para mudanças e/ou adaptação de acordo com as necessidades da instituição. Expansibilidade: Tenha capacidade de expansão conforme a demanda documental da instituição.

Para Schellenberg (2006. p. 88), "[...] os métodos de classificação podem ser divididos em três tipos: funcional, organizacional e por assuntos. O autor americano, entretanto, descarta de maneira definitiva a possibilidade da classificação de documentos de arquivo ser feita por assunto".

De acordo com a Resolução N. 14 do CONARQ, os assuntos devem representar as funções e atividades do organismo produtor, inclusive indica que as funções, atividades e documentos foram genericamente chamados de assunto.

Flores e Lampert (2012) citados por Padilha e Spudeit (2014, p. 132 e 133) afirmam:

[...] que os métodos funcional, estrutural e por assunto, são os mais comuns a serem utilizados, sendo que o método funcional é o que parece ser o mais adequado para os variados contextos dos arquivos, por ser flexível, e também por abrir margem para novas classes a cada nova função e/ou atividade.

O autor Schellenberg (2006, p. 88) menciona que "[...] os 
documentos públicos, geralmente, necessita ser agrupados segundo a organização e função, a exceção a essa regra se dá para certos tipos de documentos, tais como os que não se originam da ação governamental ou não estão a ela vinculados".

Continuando na linha de raciocínio do autor Schellenberg (2006, p. 88): "A classificação organizacional ou estrutural não é a adequada". Isso por que "[...] estruturas organizacionais das organizações contemporâneas são instáveis, com mudanças rápidas e que nem sempre são resultado de uma análise funcional, mas de condicionantes políticos, muitas das vezes, estranhos ao ambiente organizacional".

Para Foscarini (2010, p. 43), "[...] a prática de classificar documentos se origina da necessidade de explicitar o "vínculo arquivístico", que existe entre todos os documentos que participam da mesma atividade desde o momento de sua criação".

Desse modo, a referida autora acredita que, a partir do momento da classificação, as relações estabelecidas entre os arquivos aparecem de modo efetivo a entender o significado de cada documento, assim como a relação entre eles. Dessa forma, a estrutura total de documentos necessita ser compreendida e perpetuada ao longo do tempo.

Há um método pouco conhecido de classificação que é por tipologia documental, iniciado na década de 1980. Como esse método é muito recente, ainda não existe uma profunda fundamentação teórica desenvolvida sobre esse tema. (MELLO; RODRIGUES, 2012, p. 9)

De acordo com Mello e Rodrigues (2012), o método por tipologia documental foi iniciado pelo grupo de Trabajo de Archiveros Municipales de Madrid e permite que se faça a padronização das séries documentais.

Marques (2012) explicou que esse método pode parecer, em primeira instância, seguro e prático, porém impede que, futuramente, a classificação tenha alterações e que se tenha inclusão de documentos que não estavam previamente estipulados.

Sousa (2014, p. 21) aponta três fatores importantes para operar na classificação de documentos. Primeiro: os objetivos da classificação têm que auxiliar na recuperação de documentos, não ficarem apenas confinados à preservação do vínculo arquivístico. Segundo: reconhecer as dificuldades da aplicação da classificação funcional na recuperação de documentos e informação de maneira rápida e eficiente, principalmente nas fases corrente e intermediária. Terceiro: conhecer e considerar as diferenças e múltiplas facetas 
informacionais contidas nos documentos de arquivo, transformando "[...] um sistema de controle de documentos em um sistema de informação".

\subsection{Planos de classificação em arquivos}

Os Planos de Classificação também são conhecidos por Códigos de Classificação na literatura. Segundo o Dicionário Brasileiro de Terminologia Arquivística, em seu conceito de Plano de Classificação:

Esquema de distribuição de documentos em classes, de acordo com métodos de arquivamento específicos, elaborados a partir do estudo das estruturas e funções de uma instituição e da análise do arquivo por ela produzido. Expressão geralmente adotada em arquivos correntes (ARQUIVO NACIONAL, 2005, p. 132).

Em conformidade com Faria (2006, p. 35), "o instrumento de gestão que organiza, em um plano intelectual, os tipos documentais produzidos e/ou recebidos, conforme os critérios definidos pela classificação documental adotada e os organiza de forma hierárquica por meio das unidades de classificação".

"A Classificação em arquivos tem como resultado um produto: o instrumento de classificação [plano de classificação]. E é nele que deverão estar representadas as equivalências hierárquicas" (SOUSA, 2008).

Os Planos de Classificação são utilizados nas fases corrente, intermediária e permanente dos documentos. No cenário arquivístico, os Planos de Classificação são elaborados e empregados de modo a racionalizar os procedimentos na gestão documental e integrar a política de informação da Instituição, seja pública ou privada (RIOS; CORDEIRO, 2010).

Descrevem Rios e Cordeiro (2010, p. 126): os Planos de Classificação têm como objetivo "[...] agrupar documentos sobre um mesmo assunto, representado por uma notação (codificação) e, também, implica na organização física dos documentos arquivados para a sua busca (recuperação) notacional".

Rios e Cordeiro (2010) mencionam que a expressão assunto deva ser considerada a partir de um conceito partindo do conteúdo do documento, descrito por termos ou notações que surgiriam nos planos de classificação. Porém, de acordo com as autoras, essa ideia de assunto em Planos de Classificação precisa ser vista de 
modo lato, isso porque os assuntos estão presentes em cada classe, de acordo com a disposição hierárquica da cadeia que reflete as funções e atividades da instituição. O assunto poderá ser visto tanto de modo primário: uma disciplina, período; como de modo secundário: completado com a indicação de uma forma intelectual, de apresentação e física.

Uma das dificuldades de se elaborar um Plano de Classificação recai sobre a realocação adequada das funções e atividades do órgão produtor com relação aos documentos. Nesse sentido, Lopes (1996, p. 92) menciona que "[...] no Brasil e em muitos países é comum o abismo entre "funções" e "atividades". A primeira é abstrata, definida na formalidade dos documentos de uma organização. A segunda é concreta; conhece-se uma organização pelo que efetivamente realiza".

Para Gonçalves (1998), o uso de método por "assunto" necessita ser feito de forma esclarecedora, para que não seja confundido como "função" ou como "tema", evitando que no desenvolvimento do plano de classificação os documentos não estejam agrupados em suas devidas classes e subclasses.

Visando o conceito de teoria facetada a partir do assunto:

A Classificação Facetada trata-se de um tipo de classificação capaz de identificar características comuns a diversas categorias de um assunto, organizando-o em partes denominadas de facetas. Envolve dois processos diferenciados, porém complementares: a análise de assunto em facetas e a síntese dos elementos constituintes do mesmo, sendo portanto, aplicável a qualquer que seja área do conhecimento (DUARTE et al., 2010, p. 47).

Conforme aponta Piedade:

Os sistemas modernos, os ditos sistemas em facetas [tentam incluir a ideia de faceta], são elaborados à base de conceitos simples e dão grande importância aos relacionamentos, atribuindo ao ato de classificar a tarefa de construir os símbolos de classificação pelo relacionamento de conceitos originários de diversas facetas (PIEDADE, 1983, p. 30).

Observado por Rios e Cordeiro (2010, p. 126), "baseada na ideia de assunto, na teoria da classificação facetada podemos entender que a declaração de assunto de um documento poderá ser a manifestação, [...], de uma das facetas: coisa/produto (ou de parte da coisa/parte do produto) ação (processo/operação/atividade), 
material, agente/instrumento, propriedades, lugar, tempo e forma".

Em suma ao exposto pelas autoras, os planos de classificação de documentos arquivísticos organizados pela estrutura funcional refletem os assuntos resultantes da faceta ação.

\subsection{Procedimentos de classificação em arquivos}

Um dos primeiros passos a se seguir acerca da elaboração dos Planos de Classificação está no conhecimento da estrutura organizacional em âmbito geral no que concerne ao seu contexto perante a instituição. Isso significa conhecer, primeiramente, a organização/criador e, num segundo momento, conhecer as atividades e funções desempenhadas, as atribuições e finalidades alcançadas em torno dos processos no decorrer das atividades realizadas na Instituição. De acordo com Héon (1995, traduzido por Sousa, 2008), a base de classificação em arquivos está no princípio da proveniência em seus dois níveis: respeito aos fundos e a ordem original, que traz a ideia de conhecer o criador do arquivo seja pessoa física ou jurídica.

É uma ideia interessante de se analisar, pois para classificar é preciso compreender as funções e atividades, bases de sustentação para a elaboração e aplicação dos Planos de Classificação.

Nas palavras de Barbosa (1969, p. 33) a notação de um sistema de classificação é "[...] o conjunto de símbolos que representa o assunto ou os assuntos dos livros. É imprescindível a qualquer sistema por ser a representação simbólica dos assuntos".

Como nota Piedade (1983, p. 38) a notação é: "[...] o conjunto de símbolos destinados a representar os termos da classificação, traduzindo em linguagem codificada o assunto dos documentos, e permitindo sua localização nas estantes, nos catálogos e nas tabelas de classificação".

Para Héon (1995, p. 77, traduzido por Rios e Cordeiro, 2010), "[...] o plano de classificação fornece a prova tangível da aplicação do princípio de respeito aos fundos de arquivos".

Sousa (2008) aponta que o primeiro nível de divisão em um Plano de Classificação é em todo caso a missão do produtor. As funções viriam a ser o segundo nível de divisão. Por fim, nas demais divisões surgem diferentes princípios de divisão, como atividades, tipologia documental etc.

Após a discussão sobre a adoção do princípio de divisão e a estruturação das classes, a ação recai sobre a criação de um método 
que indique as ordens estabelecidas, podendo ser entendido como notação, codificação ou mais comumente conhecido por código de classificação, que seria o instrumentalizador das atividades anteriores: as de classes e princípios.

A notação e seu caráter revelador da estrutura do Plano de Classificação, em razão da busca da simplicidade e flexibilidade, isto é, não precisa ser engessada a ponto de não permitir novas classes subclasses em sua estrutura, a fim de abrigar novos documentos de natureza variáveis. É necessário ater-se, principalmente, em torno da organicidade, sendo assim:

[...] a notação facilita a reconstituição dos dossiês, sobretudo aqueles que são compostos de documentos de formas variadas ou registrados sobre diversos suportes de informação. Como o mesmo código deve ser utilizado por documentos que se reportam ao mesmo assunto, mas conservados em diferentes suportes [...], é mais fácil recuperar os componentes de um dossiê (PIAF, 2008, p. 9, traduzido por RIOS e CORDEIRO, 2010).

Segundo Sousa (2008), é possível encontrar, também, as informações necessárias para a elaboração dos planos de classificação documental, a partir de sua missão, estrutura, funções, atividades e procedimentos formais e informais, e levantamento dos documentos acumulados - condições de produção e acumulação e criação de tipologias documentais.

O CONARQ adotou um modelo de classificação decimal, formalizado na Resolução N. 14 (2001), ou seja, cada conjunto numérico é dividido em dez classes. As classes representam as funções desempenhadas pela instituição e podem se subdividir em subclasses. Dentro do Plano de Classificação, existem numerações vazias que precisam ser preenchidas com novas funções e atividades que poderão ser criadas no futuro. É interessante a preocupação que a equipe do CONARQ teve ao elaborar esse plano para que não fosse engessado. Ao mesmo tempo, sua organização possibilita, de forma clara e precisa, suas classes e subclasses, de acordo com os assuntos inerentes.

O Plano de Classificação do CONARQ serve de referência para outros órgãos criarem seus Planos de Classificação, claro que de acordo com suas próprias características, adequando-se aos procedimentos de gestão documental em âmbito Arquivístico.

O Plano do CONARQ é destinado a atividades-meio da administração pública brasileira, em que são criados os Planos conforme as diretrizes legais para a esfera de competência, como é 


\section{PROCEDIMENTOS METODOLÓGICOS}

O estudo comparativo sobre planos de Classificação baseou-se na pesquisa bibliográfica e descritiva exploratória, realizada durante o ano de 2016, como Trabalho de Conclusão de Curso de Graduação em Arquivologia na Universidade Federal de Santa Catarina.

A presente pesquisa se caracteriza como bibliográfica. Considera-se o conceito de pesquisa bibliográfica proposto por Gil (2010, p. 29) aquela pesquisa que:

[...] é elaborada com base em material publicado. Tradicionalmente esta modalidade de pesquisa inclui material impresso como livros, revistas, jornais, teses, dissertações e anais de eventos científicos. Todavia em virtude da disseminação de novos formatos de informação, estas pesquisas passaram a incluir outros tipos como discos, fitas magnéticas bem como o material disponibilizado pela internet.

Do ponto de vista da análise dos dados, a pesquisa descritiva, segundo Rudio (1986, p. 56), "[...] está interessada em descobrir e observar fenômenos, procurando descrevê-los, classificá-los e interpretá-los". Para Andrade (1999. p. 17), na pesquisa descritiva, "[...] os fatos são observados, registrados, analisados, classificados e interpretados, sem que o pesquisador interfira sobre eles".

Conceituam Silva e Menezes (2005, p. 21):

[...] a pesquisa descritiva visa descrever as características de determinada população ou fenômeno ou o estabelecimento de relações entre variáveis. Envolve o uso de técnicas padronizadas de coleta de dados: questionário e observação sistemática. Assume, em geral, a forma de levantamento.

Como observam Barros e Lehfeld (2000, p. 70), neste tipo de pesquisa, "não há interferência do pesquisador, isto é, ele descreve o objeto de pesquisa. Procura descobrir a frequência com que um fenômeno ocorre, sua natureza, característica, causas, relações e conexões com outros fenômenos".

Relata Santos (2012, p. 197) que "na pesquisa descritiva é feita a descrição das características de uma determinada população, estudo descritivo de determinado fenômeno com suas variáveis". 
A pesquisa documental foi realizada a partir da análise da Gestão de Documentos do Plano de Classificação de Documentos por Assunto da ANEEL (Versão 2003). Foi escolhido o Plano de Classificação da ANEEL, pois traz todas as características do Plano de Classificação do CONARQ nas atividades-meio, que já é conhecimento de profissionais da área arquivística, sendo fácil a sua interpretação por consequência coleta de dados.

Os Planos de Classificação da Administração Local de Portugal e o Cuadro de Clasificación de Fondos para a Administração Local da Espanha foram escolhidos, sobretudo pela proximidade de entendimento das línguas, favorecendo também a interpretação e coleta de dados, principalmente no caso de Portugal, por ser do mesmo idioma.

Segundo os estudos dos autores abaixo, a pesquisa documental tem as seguintes características:

A pesquisa documental trilha os mesmos caminhos da pesquisa bibliográfica, não sendo fácil por vezes distingui-las. A pesquisa bibliográfica utiliza fontes constituídas por material já elaborado, constituído basicamente por livros e artigos científicos localizados em bibliotecas. A pesquisa documental recorre a fontes mais diversificadas e dispersas, sem tratamento analítico tais como: tabelas estatísticas, jornais, revistas, relatórios, documentos oficiais, cartas, filmes, fotografias, pinturas, tapeçarias, relatórios de empresas, vídeos de programas de televisão, etc. (MATOS; VIEIRA, p. 40).

Segundo Marconi e Lakatos (2010, p. 157), "a característica da pesquisa documental é que a fonte de coleta de dados está restrita a documentos, escritos ou não, constituindo o que se denomina de fontes primárias. Estas precisam ser feitas no momento em que o fato ou fenômeno ocorre, ou depois".

De acordo com Santos (2012, p. 198):

A pesquisa documental é trabalhada com base em documentos que não receberam tratamento de análise e síntese. Embora se identifique com a pesquisa bibliográfica, esta só se realiza sobre documentos analisados e pertencentes a autores que deram o estudo pronto e acabado. As vantagens deste tipo de pesquisa são a confiança nas fontes documentais, como essenciais para qualquer estudo, o baixo custo e o contato do pesquisador com documentos originais. Entre as desvantagens estão a falta de objetividade, a falta de representatividade e a subjetividade dos documentos. 
Esta é uma pesquisa documental, visto que se utiliza de fontes diversificadas. A pesquisa documental tem essa característica de utilizar documentos escritos ou não, sem tratamento analítico nem sínteses realizadas pelo autor. Os autores Santos, Matos e Vieira se complementam em identificar que a pesquisa documental recorre a diversos tipos de fontes. Santos ainda menciona que a vantagem da pesquisa documental é a confiança nas fontes documentais, baixo custo e a possibilidade de acessar documentos originais.

O período do desenvolvimento do projeto até as conclusões da pesquisa aconteceu entre fevereiro e novembro de 2016. A análise e discussão dos resultados estão pautadas na Lei n. 8.159, de 08 de janeiro de 1991, que dispõe sobre a política nacional de arquivos públicos e privados e dá outra providência a seguir apresentada.

De acordo com o objetivo deste estudo comparativo, foi realizada a identificação dos quadros de classificação que representassem de forma a ser compreensível o entendimento das características de cada um dos três planos. A comparação entre os planos deu-se através da observação dos níveis e/ou seções de codificação utilizados em cada um dos três planos e, também, através da estrutura de classes que apresenta cada um dos três planos, por meio de quadro comparativo e tabelas de temporalidade.

\section{RESULTADOS DA PESQUISA}

Através de estudos e leituras, foram realizadas análises de três Planos de Classificação distintos: ANEEL, Plano de Classificação para Administração Local de Portugal e Cuadro de Clasificación de fondos de Archivos Municipales da Espanha. Pôdese identificar algumas características similares nos Planos de Classificação estudados: estrutura funcional e codificação por níveis e/ou seções.

O Plano de Classificação da ANEEL apresenta-se mais sucinto que os demais. Provavelmente, por haver uma quantidade menor de documentos, não necessite de uma quantidade maior de mais níveis de codificação em relação aos outros dois planos internacionais analisados. O Plano do CONARQ gerou a base de criação do Plano da ANEEL, mais simples e compreensível do que os Planos de Portugal e Espanha. 


\subsection{Plano de Classificação (ANEEL)}

A ANEEL (2016), como agência do governo federal brasileiro, gera e recebe uma quantidade de documentos provenientes do exercício das suas funções. São documentos que registram a produção, transmissão, distribuição e comercialização de energia elétrica e auxiliam diretamente na implementação de políticas e diretrizes, controle de funções e atividades desenvolvidas pela ANEEL.

Com o intuito de realizar um serviço de qualidade, a ANEEL implementa, na sua política de gestão, em todas as unidades, os recursos de geração, recebimento, tramitação, arquivamento corrente, arquivamento intermediário, avaliação, guarda permanente e eliminação.

De acordo com a Lei n. 8.159, no "Art. $3^{\circ}$ - Considera-se gestão de documentos o conjunto de procedimentos e operações técnicas referentes à sua produção, tramitação, uso, avaliação e arquivamento em fase corrente e intermediária, visando a sua eliminação ou recolhimento para guarda permanente".

O Plano de Classificação de Documentos por Assuntos da Agência Nacional de Energia Elétrica - ANEEL (2003) é estruturado por meio de assuntos previamente coletados por cada setor da Agência, e os tipos documentais e seus respectivos assuntos tratados também foram descritos na tabela de temporalidade.

Para as atividades-meio são adotadas, como base, a Tabela de Classificação, Temporalidade e Destinação de documentos de Arquivo, relativos às da Administração Pública aprovadas pelo CONARQ.

\subsubsection{Estrutura do Plano de Classificação}

A Tabela do CONARQ e ANEEL segue a mesma estrutura de codificação:

[...] adotou-se o modelo de código de classificação decimal. Como o próprio nome indica, o sistema decimal de classificação por assuntos constitui-se num código numérico dividido em dez classes e estas, por sua vez, em dez subclasses e assim sucessivamente. As dez classes principais são representadas por um número inteiro, composto de três algarismos, como se segue: Classe 000; Classe 100; Classe 200; Classe 300; Classe 400; Classe 500; Classe 600; Classe 700; Classe 800; Classe 900. (CONARQ, 2001 p.9) 
A Tabela de Temporalidade da ANEEL (2003) foi disposta, portanto, em 3 classes:

TABELA DE TEMPORALIDADE 1 - Estrutura do Plano

\begin{tabular}{|l|l|}
\hline Classe 000 & ADMINISTRAÇÃO GERAL \\
\hline Classe 100 a 800 & ATIVIDADES ESPECÍFICAS \\
\hline Classe 900 & ASSUNTOS DIVERSOS \\
\hline
\end{tabular}

FONTE: ANEEL, 2003.

$\mathrm{Na}$ Tabela 2, as Classes do plano de classificação da ANEEL são divididas em subclasses e estas em grupos e subgrupos:

TABELA DE TEMPORALIDADE 2 - Divisão de Classes

\begin{tabular}{|l|l|}
\hline CLASSE 000 & ADMINISTRAÇÃO GERAL \\
\hline SUBCLASSE 010 & ORGANIZAÇÃO E FUNCIONAMENTO \\
\hline GRUPO 012 & COMUNICAÇÃO SOCIAL \\
\hline SUBGRUPOS & RELAÇOEES COM A IMPRENS \\
012.1 & CREDENCIAMENTO DE JORNALISTAS \\
012.11 & \\
\hline
\end{tabular}

FONTE: ANEEL, 2003.

Observamos que a Tabela 2 lembra muito as recomendações do CONARQ sobre os Planos de Classificação, isso por que foi criado a partir do Código de Classificação de Documentos de Arquivo para a Administração Pública: Atividadesmeio do Arquivo Nacional. E, posteriormente, aprovado pelo CONARQ, adotado pelas instituições de esfera pública no Brasil, inclusive a ANEEL.

\subsection{Planos de Classificação Ibéricos}

Serão analisados os Planos de Classificação de Portugal (Administração Local) e Espanha (O Cuadro de Clasificación de fondos de Archivos Municipales). Foram escolhidos, sobretudo, pela proximidade de entendimento das línguas, favorecendo, também, a interpretação e coleta de dados, principalmente no caso de Portugal. 4.2.1 Portugal

Nesta pesquisa, foi analisado, por meio de leituras, os Planos de Classificação da Administração Pública de Portugal e Espanha.

O Plano de Classificação para a Administração Local em Portugal foi desenvolvido em níveis, sendo que os dois primeiros 
representam as funções e as subfunções da administração pública (Macroestrutura Funcional) e o 3.ำ nível representa os Processos de Negócio.

A Macroestrutura Funcional (MEF) desenvolveu para a administração pública uma representação das funções e subfunções desempenhadas pelos distintos organismos, visando apoiar a elaboração de planos de classificação funcionais. (SILVA, 2013, p. 3) "A Macroestrutura Funcional tem, na sua gênese, um modelo conceptual que assenta na definição de quatro domínios de funções":

- Funções de apoio à governação;

- Funções de suporte à gestão de recursos;

- Funções normativa, reguladora e fiscalizadora;

- Funções produtiva e prestadora de serviços (SILVA, 2013, p. 3)

TABELA DE TEMPORALIDADE 3 - Plano de Classificação para Administração Local

\begin{tabular}{|c|l|}
\hline $\begin{array}{c}\text { FUNÇÃO 100 } \\
\text { Os Processos } \\
\text { de Negócio }\end{array}$ & \\
\hline 100 & ORDENAMENTO JURIDICO E NORMATIVO \\
\hline 100.10 & Elaboração de diplomas jurídico-normativos e de normas técnicas \\
\hline 100.10 .01 & Produção e comunicação de atos legislativos \\
\hline 100.10 .02 & Produção e comunicação de atos regulamentares gerais \\
\hline 100.10 .03 & Produção e comunicação de atos regulamentares locais \\
\hline 100.10 .04 & Produção e comunicação de regras institucionais \\
\hline 100.10 .05 & $\begin{array}{l}\text { Produção e comunicação de instruções para aplicação de } \\
\text { diplomas jurídico-normativos }\end{array}$ \\
\hline 100.10 .06 & Produção e comunicação de normas técnicas \\
\hline 100.10 .07 & Aprovação e comunicação de convenções internacionais \\
\hline 100.10 .08 & $\begin{array}{l}\text { Comunicação de decisões dos tribunais a que a lei confira força } \\
\text { obrigatória geral }\end{array}$ \\
\hline 100.20 & Interpretação da legislação e das normas \\
\hline 100.20 .01 & $\begin{array}{l}\text { Produção de pareceres jurídicos de interpretação de diplomas } \\
\text { jurídico-normativos }\end{array}$ \\
\hline 100.20 .02 & Produção de orientações para a interpretação da norma técnica \\
\hline 100.20 .03 & $\begin{array}{l}\text { Produção e comunicação de decisões de uniformização de } \\
\text { jurisprudência }\end{array}$ \\
\hline
\end{tabular}

FONTE: Arquivo Municipal de Torres Vedras, 2013.

Observando a tabela, é possível fazer um comparativo com o Plano do CONARQ. Percebeu-se que há algumas diferenças.

Em relação à terminologia no plano de Classificação de Portugal, emprega-se o termo "níveis" e utilizam-se três blocos de dígitos: 
O 1. elemento do código numérico (bloco de três dígitos) corresponde à classe de 1ำ nível, isto é, à representação da Função;

O 2.. elemento do código (bloco de dois dígitos) corresponde à classe de $2^{0}$ nível, isto é, à representação da Subfunção;

O 3. elemento do código (bloco de três dígitos) corresponde à classe de $3^{\circ}$ nível, isto é à representação do processo de negócio (SILVA, 2013, p. 7).

Cada nível que se segue possui características em comuns com os demais: (Silva, 2013, p. 8) "Cada nível é definido por um código, título, descrição, notas de aplicação e de exclusão, palavras-chave para índice, visando apoiar a utilização do plano de classificação".

\subsubsection{Espanha}

"Assim como em Portugal, o Grupo de Archiveros Municipales de Madrid elaborou um Plano de Classificação funcional, porém diferentemente de Portugal, integrou-se o arquivo tradicional em papel e o arquivo digital criando o Cuadro de Clasificación de fondos de Archivos Municipales". (SILVA, 2013, p. 9)

O plano de classificação apresenta [...] por base os órgãos, as funções e os assuntos, [...] [predominando] a classificação funcional. O Fundo Geral do Município, assim como os subfundos não são objecto de codificação. Dentro de cada subfundo, a estrutura classificativa segue as orientações da ISAD (G), correspondendo às classes de 1.ำ nível a Secção (SC), de segundo nível a Subsecção, de terceiro nível a Subsubsecção e de quarto nível a série, como testemunha o exemplo a seguir, ao qual associámos, por vezes, a correspondente Classe de $1 . . \circ$ e/ou 2.. níveis do Plano de Classificação para a Administração Local, em Portugal (SILVA, 2013, p. 9 e 10).

TABELA DE TEMPORALIDADE 4 - Centros culturales

\begin{tabular}{|l|l|}
\hline 03.08 .03 .01 & Correspondencia de los Centros Culturales \\
\hline 03.08 .03 .02 & Expedientes de creación de centros culturales \\
\hline 03.08.03.03 & $\begin{array}{l}\text { Expedientes de programación y actividades de los centros } \\
\text { culturales }\end{array}$ \\
\hline 03.08.03.04 & Informes de los centros culturales \\
\hline
\end{tabular}


03.08.03.05 Memorias de los centros culturales

FONTE: Arquivo Municipal de Torres Vedras, 2013.

Vemos, portanto, um índice remissivo, ordenado alfabeticamente, auxiliando, assim, os utilizadores do Plano de Classificação.

A título de exemplo, apresentam-se as séries da subsubsecção 03.08.03.00 Centros culturales, cuja designação considera todos os centros culturais existentes num município, independentemente do seu número, justificando-se pelo volume reduzido de documentos criados no âmbito desta 'função': (SILVA, 2013, p. 14)

Ao verificar os planos de classificação, pode-se apresentar, no quadro 1, a comparação entre os mesmos.

QUADRO 1 - Comparativa dos Planos de Classificação da Península lbérica

\begin{tabular}{|c|c|c|c|c|}
\hline $\begin{array}{c}\text { Nivel de } \\
\text { Identificación }\end{array}$ & $\begin{array}{c}1^{\circ} \text { - nivel de } \\
\text { desagregación }\end{array}$ & $\begin{array}{c}2^{\circ} \text { nivel de } \\
\text { desagregación } \\
\text { SERIES }\end{array}$ & $\begin{array}{c}3^{\circ} \text { nivel de } \\
\text { desagregación }\end{array}$ & $\begin{array}{c}4^{\circ} \text { nivel de } \\
\text { desagregación }\end{array}$ \\
\hline $\begin{array}{c}\text { Os Processos de } \\
\text { Negócio }\end{array}$ & $\begin{array}{c}100 \\
\text { ORDENAMENTO } \\
\text { JURÍDICO E } \\
\text { NORMATIVO }\end{array}$ & $\begin{array}{c}100.10 \\
\text { ELABORAÇÃO } \\
\text { DE DIPLOMAS } \\
\text { JURÍDICO- } \\
\text { NORMATIVOS E } \\
\text { DE NORMAS } \\
\text { TÉCNICAS } \\
100.20 \\
\text { INTERPRETAÇÃO } \\
\text { DA LEGISLAÇÃO } \\
\text { E DAS NORMAS }\end{array}$ & $\begin{array}{c}100.10 .01 \\
\text { Produção e } \\
\text { comunicação de } \\
\text { atos legislativos } \\
100.10 .02 \\
\text { Produção e } \\
\text { comunicação de } \\
\text { atos } \\
\text { regulamentares } \\
\text { gerais } \\
100.10 .03 \\
\text { Produção e } \\
\text { comunicação de } \\
\text { atos } \\
\text { regulamentares } \\
\text { locais } \\
100.10 .04 \\
\text { Produção e } \\
\text { comunicação de } \\
\text { regras } \\
\text { institucionais }\end{array}$ & \\
\hline
\end{tabular}

\begin{tabular}{|c|c|c|c|c|}
\hline $\begin{array}{c}\text { Nivel de } \\
\text { Identificación }\end{array}$ & $\begin{array}{c}1^{10} \text { nivel de } \\
\text { desagregación }\end{array}$ & $\begin{array}{c}2^{\circ} \text { nivel de } \\
\text { desagregación } \\
\text { SERIES }\end{array}$ & $\begin{array}{c}3^{\circ} \text { nivel de } \\
\text { desagregación }\end{array}$ & $\begin{array}{c}4^{\circ} \text { nivel de } \\
\text { desagregación }\end{array}$ \\
\hline
\end{tabular}




\begin{tabular}{|c|c|c|c|}
\hline $\begin{array}{c}\text { FONDO GENERAL } \\
\text { DEL } \\
\text { AYUNTAMIENTO }\end{array}$ & $\begin{array}{c}\text { SUBFONDO } \\
\text { AYUNTAMIENTO }\end{array}$ & $\begin{array}{c}03.00 .00 \\
\text { SERVICIOS (SC) } \\
\text { 03.08.03 Centros } \\
\text { culturales }\end{array}$ & \begin{tabular}{|c}
03.08 .03 .01 \\
Correspondencia \\
de los Centros \\
Culturales \\
03.08 .03 .02 \\
Expedientes38 de \\
creación de \\
centros culturales \\
03.08 .03 .03 \\
Expedientes de \\
programación y \\
actividades de los \\
centros culturales \\
03.08 .03 .04 \\
Informes de los \\
centros culturales \\
03.08 .03 .05 \\
Memorias de los \\
centros culturales
\end{tabular} \\
\hline
\end{tabular}

FONTE: Dados da pesquisa, 2016.

Este quadro apresenta os níveis de separação (desagregación) dos Planos de Classificação da Península Ibérica, sendo o primeiro referente ao plano de Portugal e o segundo da Espanha. O Fundo Geral do Município na Espanha, assim como os Subfundos, não são objetos de codificação. A Administração Local de Portugal não utiliza o 4ำ nível de separação, utiliza a Função, Subfunção e a representação dos Processos de Negócio.

"É a partir desses níveis (de separação) onde se verificam as ações e operações classificatórias, cujo propósito será será garantir a organização adequada dos documentos" (ARCHIVO GENERAL DE LA NACIÓN 2004, tradução nossa).

\section{CONCLUSÕES}

A pesquisa observou a elaboração de Plano de Classificação que seja plausível com as condições e necessidades documentais dos órgãos públicos.

Afirmar que os objetivos delimitados nesta pesquisa foram alcançados. Foi possível analisar vários Planos de Classificação e de diferentes países, o que nos acrescenta mais conhecimento na área.

O Fundo Geral do Município na Espanha, assim como os Subfundos, não são objetos de codificação. A Administração Local

\footnotetext{
1 Archivo General de la Nación de México. Cuadro general de clasificación archivística. Instructivo para su elaboración, 2004. Disponível em: <http://www.agn.gob.mx/lineam/instructivo\%20para\%20el\%20cuadro\%20de\%20clasifi cacion.pdf >. Acesso em: 30 nov. 2016.
} 
de Portugal não utiliza o 4ํㅡㄴ nel de separação, mas, sim, a Função, Subfunção e a representação dos Processos de Negócio.

Foi possível estabelecer uma conexão com Portugal e Espanha e fazer a análise paralela de seus respectivos Planos de Classificação, comparando-os também com o Plano da empresa brasileira ANEEL.

Uma característica que diferencia O Plano da ANEEL em relação ao espanhol e português se encontra na codificação. $O$ CONARQ adotou a codificação que é distribuída em todas as classes até os últimos níveis. Na Espanha, o Fundo Geral do Município, assim como os Subfundos, não são objetos de codificação. O Plano de Classificação de Portugal já apresenta uma maior semelhança em relação ao Brasil, pois utiliza codificação em todos os níveis, mas, diferentemente da Espanha, não possui o $4^{\circ}$ nível de separação (desagregación).

Uma sugestão é de que os representantes de Arquivos Nacionais dos países Sul-americanos se reunissem para elaborar um Plano de Classificação de forma conjunta, favorecendo os futuros estudos de casos e possíveis aplicações de melhoria num contexto muito mais amplo, porém é preciso frisar as especificidades de cada país com relação à legislação arquivística. A padronização nas codificações, por exemplo, poderia trazer um melhor entendimento das funções e atividades nos Planos de Classificação em diferentes países.

\section{REFERÊNCIAS}

ANDRADE, Maria Margarida de. Introdução à metodologia do trabalho científico: elaboração de trabalhos na graduação. 4. Ed. São Paulo: Atlas, 1999.

ANEEL. Órgão Governamental. Plano de Classificação de Documentos por Assunto da ANEEL. 2003. Disponível em:

<http://www.aneel.gov.br/arquivos/word/Plano_Classificacao_unificado_intra net_atualizado\%20em\%2027-11-2003.doc.>. Acesso em: 02 nov. 2016.

ARCHIVO GENERAL DE LA NACIÓN DE MÉXICO. Cuadro general de clasificación archivística. Instructivo para su elaboración, 2004. Disponível em:

<http://www.agn.gob.mx/lineam/instructivo\%20para\%20el\%20cuadro\%20de \%20clasificacion.pdf>. Acesso em: 30 nov. 2016.

ARQUIVO NACIONAL (Brasil). Dicionário Brasileiro de Terminologia

Arquivística. Rio de Janeiro: Arquivo Nacional, 2005. Disponível em: <http://www.arquivonacional.gov.br/Media/Dicion Term Arquiv.pdf>. Acesso 
em: 19 jun. 2016.

BARBOSA, Alice Príncipe. Teoria e prática dos sistemas de classificação bibliográfica. Rio de Janeiro: IBBD, 1969.

BARROS, Aidil Jesus da Silveira; LEHFELD, Neide Aparecida de Souza. Fundamentos de Metodologia. 2. ed. São Paulo: Makron Books, 2000.

BRASIL. Lei n. 8159, de 8 de janeiro de 1991. Dispõe sobre a política nacional de arquivos públicos e privados e dá outras providências.. Lei 8159. Brasília, DF. Disponível em:

<http://www.planalto.gov.br/ccivil_03/leis/L8159.htm >. Acesso em: 22 set. 2016.

CONARQ. Conselho Nacional de Arquivos. Classificação, Temporalidade e Destinação de Documentos de Arquivo Relativos às Atividades-Meio da Administração Pública. 2001. Disponível em:

<http://www.conarq.arquivonacional.gov.br/images/publicacoes_textos/Codig o_de_classificacao.pdf >. Acesso em: 22 set. 2016.

DUARTE, Elizabeth Andrade et al. Classificação facetada: um olhar sobre a construção de estruturas semânticas. Revista Digital de Biblioteconomia e Ciência da Informação, Campinas, v. 7, n. 2, p. 46-58, 2010. Disponível em: $<$ http://periodicos.sbu.unicamp.br/ojs/index.php/rdbci/article/view/1956/2077>. Acesso em: 22 ago. 2016.

FARIA, Wadson Silva. A normalização dos instrumentos de gestão arquivística no Brasil: um estudo da influência das resoluções do Conarq na organização dos arquivos da Justiça Eleitoral Brasileira. Dissertação (Mestrado em Ciência da Informação) - Faculdade de Economia, Administração, Contabilidade e Ciência da Informação e Documentação. Departamento de Ciência da Informação e Documentação da Universidade de Brasília (UnB), Brasília, 2006. Disponível em: <http://repositorio.unb.br/bitstream/10482/2757/1/Dissert\%20Wadson\%20Sil va\%20Faria.pdf>. Acesso em: 22 ago. 2016.

FOSCARINI, Fiorella. 2010. "La clasificación de documentos basada en funciones: comparación de la teoria e y la práctica." Tábula: Estudios Archivísticos de Castilla y León 13: 41-57. Disponível em:

<publicaciones.acal.es/index.php/tabula/article/view/241/0 >. Acesso em: 21 set. 2016.

GIL, Antonio Carlos. Como Elaborar Projetos de Pesquisa. 5.ed. São Paulo: Atlas, 2010. Disponível em:

$<$ https://professores.faccat.br/moodle/pluginfile.php/13410/mod_resource/co ntent/1/como_elaborar_projeto_de_pesquisa_-_antonio_carlos_gil.pdf>. Acesso em: 22 ago. 2016.

GONÇALVES, Janice. Como classificar e ordenar documentos de arquivo. São Paulo: Arquivo do Estado: Imesp, 1998. 
HÉON, Gilles. Les plans de classification en archivistique. Archives, v. 27, n. 1, p. 73-90, 1995. Disponível em:

<http://www.archivistes.qc.ca/revuearchives/vol27_1/27-1-heon.pdf>. Acesso em: 22 ago. 2016.

LAMPERT, Sergio Renato; FLORES, Daniel. A produção e a classificação de documentos no software de gestão documental nuxeo sob a ótica arquivística. In: Congresso Nacional de Arquivologia, 5., 2012, Salvador. Anais eletrônicos... Salvador: AARQUES / ENARA, 2012. Disponível em: $<$ http://www.aaerj.org.br/ojs/index.php/informacaoarquivistica/article/view/16/ 12>. Acesso em: 21 set. 2016.

LOPES, Luis Carlos. A informação e os arquivos: teorias e práticas. Niterói: EDUFF; São Carlos: EDUFSCar, 1996.

MARCONI, Marina de Andrade Marconi; LAKATOS, Eva Maria. Fundamentos da metodologia científica. 7. ed. São Paulo: Atlas, 2010.

MARQUES, Maria Raquel Lisboa Costa. Classificação de documentos em organizações contemporâneas. 2012. 128 f. Dissertação (Mestrado) Curso de História, Universidade de São Paulo, São Paulo, 2012. Acesso em: 29 nov. 2014.

MATOS, Kelma Socorro Lopes; VIEIRA, Sofia Lerche. Pesquisa educacional: o prazer de conhecer. Fortaleza: Demócrito Rocha, 2001. 143 p.

MELLO, Silvia Lhamas; RODRIGUES, Ana Célia. A diplomática contemporânea como parâmetro para a classificação de arquivos universitários: reflexões sobre o caso da UFRJ. In: CONGRESSO BRASILEIRO DE ARQUIVOLOGIA, 17., 2012, Rio de Janeiro. Anais ... Rio de Janeiro: Associação dos Arquivistas Brasileiros, 2013. CD ROM. Disponível em: < http://apalopez.info/ivcoindear/34mello_txt.pdf>. Acesso em: 22 ago. 2016.

PADILHA, Tamara de Souza; SPUDEIT, Daniela Fernanda Assis de Oliveira. Plano de classificação de documentos: análise das metodologias utilizadas por instituições brasileiras Revista Brasileira de Biblioteconomia e Documentação, v. 10, n. 2, 2014. Disponível em: <http://basessibi.c3sl.ufpr.br/brapci/v/a/16774>. Acesso em: 08 Dez. 2016.

PIEDADE, Maria Antonietta Requiao. Introdução à teoria da classificação. 2. ed. rev. e aum. Rio de Janeiro: Interciência, 1983.

RIOS, Elaine Rosa; CORDEIRO, Rosa Inês Novais. Plano de classificação de documentos arquivísticos e a teoria da classificação: uma interlocução entre domínios do conhecimento. Perspectivas em Ciência da Informação, Belo Horizonte, v. 15, n. 2, p. 123-139, 2010. Disponível em: < http://portaldeperiodicos.eci.ufmg.br/index.php/pci/article/view/898/736>. Acesso em: 22 ago. 2016.

RUDIO, Franz Victor. Introdução ao Projeto de Pesquisa Científica. 11. ed. Petrópolis: Vozes, 1986. 
SANTOS, Izequias Estevam dos. Manual de Métodos e Técnicas de Pesquisa Científica. 9. ed. Niterói: Impetus, 2012. 384 p.

SANTOS, Vanderlei Batista dos; INNARELLI, Humberto Celeste; SOUSA, Renato Tarciso Barbosa de (Orgs). Arquivística: temas contemporâneos: classificação, preservação digital, gestão do conhecimento. 2. ed. Distrito Federal: SENAC, 2008. p. 77-172.

SCHELLENBERG, Theodore Roosevelt. Arquivos Modernos: princípios e técnicas. 6. ed. Rio de Janeiro: Fgv, 2006. 388 p.

SILVA, Carlos Guardado da. A classificação da informação arquivística da administração local nos países ibéricos: uma análise comparada. Lisboa: Arquivo Municipal de Lisboa, 2013. p. 1 - 16. Disponível em: <http://arquivomunicipal.cm-lisboa.pt/fotos/editor2/guardado_silva.pdf>. Acesso em: 02 nov. 2016.

SILVA, Edna Lúcia da; MENEZES, Estera Muszkat. Metodologia da Pesquisa e Elaboração de Dissertação. 4. ed. rev. atual. Florianópolis: UFSC, 2005. 138 p. Disponível em: < https://projetos.inf.ufsc.br/arquivos/Metodologia_de_pesquisa_e_elaboracao _de_teses_e_dissertacoes_4ed.pdf $>$. Acesso em: 22 ago. 2016.

SOUSA, Renato Tarciso Barbosa de. Os princípios arquivísticos e o conceito de classificação. In: RODRIGUES, Georgete Medleg; LOPES, IIza Leite. (Org.). Organização e representação do conhecimento na perspectiva da Ciência da Informação. Brasília: Thesaurus, 2003. p. 240-271.

Disponível em:

<http://repositorio.unb.br/bitstream/10482/1439/1/CAPITULO_PrincipiosArqu ivisticosConceitoClassifica\%C3\%A7\%C3\%A3o.pdf>. Acesso em: 22 ago. 2016.

SOUSA, Renato Tarciso Barbosa de. A classificação como função matricial do que- fazer arquivístico. In.: SANTOS, Vanderlei Batista dos; INNARELLI, Humberto Celeste; SOUSA, Renato Tarciso Barbosa de (Orgs).

Arquivística: temas contemporâneos: classificação, preservação digital, gestão do conhecimento. 2. ed. Distrito Federal: SENAC, 2008. p. 77-172.

SOUSA, Renato Tarciso Barbosa de. Alguns apontamentos sobre a classificação de documentos de arquivo. Brazilian Journal of Information Science, Marília, v. 8, n. 1, p.1-24, jan. 2014. Disponível em: $<$ http://www2.marilia.unesp.br/revistas/index.php/bjis/article/view/4246/3085 >. Acesso em: 07 jul. 2015. 
